\title{
Staging Severity of COVID-19 according to Hemostatic Abnormalities (CAHA Score)
}

\author{
Benjamin Marchandot ${ }^{1}$ Antonin Trimaille ${ }^{1}$ Anaïs Curtiaud ${ }^{1}$ Adrien Carmona ${ }^{1}$ \\ Kensuke Matsushita ${ }^{1,2}$ Chisato Sato ${ }^{1,2}$ lan Leonard-Lorant ${ }^{3}$ Laurent Sattler ${ }^{4}$ Lelia Grunebaum ${ }^{4}$ \\ Mickaël Ohana ${ }^{3}$ Patrick Ohlmann ${ }^{1}$ Laurence Jesel ${ }^{1,2}$ Olivier Morel ${ }^{1,2}$
}

\footnotetext{
${ }^{1}$ Division of Cardiovascular Medicine, Nouvel Hôpital Civil, Strasbourg University Hospital, Strasbourg, France

2 INSERM (French National Institute of Health and Medical Research), Regenerative Nanomedicine, FMTS, Strasbourg, France

${ }^{3}$ Radiology Department, Nouvel Hôpital Civil, Strasbourg University Hospital, Strasbourg, France

${ }^{4}$ Department Laboratory Haematology, Centre for Thrombosis and Haemostasis, Nouvel Hôpital Civil, Strasbourg University Hospital, Strasbourg, France
}

Thromb Haemost 2020;120:1716-1719.
Address for correspondence Olivier Morel, MD, PhD, Nouvel Hôpital Civil, University Hospital of Strasbourg, France, 1 place de l'Hôpital, Strasbourg 67000 France (e-mail: olivier.morel@chru-strasbourg.fr).
The relevance of coronavirus disease 2019 (COVID-19) coagulation abnormalities are being increasingly recognized as a substantial proportion of patients develop thromboembolic complications. $^{1-4}$ Recently, Thachil et $\mathrm{al}^{5}$ proposed a new staging classification characterizing COVID-19-associated hemostatic abnormalities (CAHA). The authors hypothesized that this staging system may enhance risk stratification in COVID-19 patients and help guiding both antithrombotic treatments and allocating scarce resources in intensive care units (ICUs) at the time of the COVID-19 pandemic.

We identified consecutive COVID-19 patients admitted to non-ICU departments and available D-dimer measurements at Strasbourg University Hospital from February 25 to April 19, 2020. COVID-19 was confirmed by a positive result of a reverse transcriptase-polymerase chain reaction assay of a specimen collected on a nasopharyngeal swab. Patients with findings typical of COVID-19 at chest computed tomography (CT) (i.e., bilateral and peripheral ground glass opacities and/or alveolar consolidations) and for whom testing for the COVID-19 virus was either inconclusive or could not be performed, were considered as confirmed COVID-19 cases after careful reviewing by a multidisciplinary team. All patients were on thromboprophylaxis. Patients were categorized according to a simplified proposed CAHA classification ${ }^{5}$ into three stages (independent, not additive) depending on the D-dimer level peak value (highest D-dimer levels during the hospital stay)-stage 1: D-dimer less than threefold above normal; stage 2: D-dimer three- to sixfold above normal; and stage 3: D-dimer greater than sixfold above normal. Platelets and activated partial thromboplastin time (aPTT) values were not taken into account. Lesions severity at CT was classified following the European Society of Radiology/European Society of Thoracic Imaging guidelines ${ }^{6}$ received

July 4, 2020

accepted after revision

July 21,2020 (c) 2020. Thieme. All rights reserved. Georg Thieme Verlag KG,

Rüdigerstraße 14,

70469 Stuttgart, Germany
DOI https://doi.org/ 10.1055/s-0040-1715836. ISSN 0340-6245. 
Table 1 Baseline characteristics, extent of COVID-19 disease on chest CT and outcomes according to a simplified CAHA classification

\begin{tabular}{|c|c|c|c|c|}
\hline & $\begin{array}{l}\text { Stage } 1 \\
\text { D-dimers < } 3 \\
\text { ULN }(n=72)\end{array}$ & $\begin{array}{l}\text { Stage } 2 \\
\text { D-dimers 3-6 } \\
\text { ULN }(n=34)\end{array}$ & $\begin{array}{l}\text { Stage } 3 \\
\text { D-dimers > } 6 \\
\text { ULN }(n=44)\end{array}$ & p-Value \\
\hline \multicolumn{5}{|l|}{ Demographic characteristics } \\
\hline Age, y & $58 \pm 15$ & $63 \pm 15$ & $62 \pm 15$ & 0.198 \\
\hline Male, $n(\%)$ & $37(51.4)$ & $18(52.9)$ & $32(72.7)$ & 0.062 \\
\hline BMI $\left(\mathrm{kg} / \mathrm{m}^{2}\right)$ & $27 \pm 5$ & $28 \pm 4$ & $28 \pm 5$ & 0.697 \\
\hline \multicolumn{5}{|l|}{ Scoring systems for estimating risk of venous thromboembolism } \\
\hline Padua score & $2.9 \pm 1.8$ & $3.7 \pm 1.8$ & $4.0 \pm 1.8$ & 0.004 \\
\hline Padua score $>4$ & $28(38.9)$ & $21(61.8)$ & $31(70.5)$ & 0.002 \\
\hline IMPROVE score & $0.80 \pm 1.04$ & $1.47 \pm 1.13$ & $1.65 \pm 1.16$ & $<0.001$ \\
\hline \multicolumn{5}{|l|}{ Laboratory findings } \\
\hline D-dimers admission, $\mathrm{ng} / \mathrm{mL}$ & $733 \pm 335$ & $1,617 \pm 660$ & $4,588 \pm 4,403$ & $<0.001$ \\
\hline $\begin{array}{l}\text { D-dimers peak, } \mathrm{ng} / \mathrm{mL} \\
\text { (peak values observed } 4.2 \pm 4.3 \mathrm{~d} \text { after admission) }\end{array}$ & $814 \pm 369$ & $2,165 \pm 448$ & $8,531 \pm 5,326$ & $<0.001$ \\
\hline $\begin{array}{l}\text { CRP admission, } \mathrm{mg} / \mathrm{L} \\
\text { (peak values observed } 3 \pm 3.4 \mathrm{~d} \text { after admission) }\end{array}$ & $85 \pm 76$ & $99 \pm 65$ & $143 \pm 89$ & 0.001 \\
\hline CRP peak, mg/L & $122 \pm 85$ & $145 \pm 88$ & $178 \pm 102$ & $<0.001$ \\
\hline $\begin{array}{l}\text { Fibrinogen peak, } \mathrm{g} / \mathrm{L} \\
\text { (peak values observed } 5 \pm 3.9 \mathrm{~d} \text { after admission) }\end{array}$ & $6.7 \pm 1.6$ & $7.3 \pm 1.7$ & $8.2 \pm 2.1$ & 0.006 \\
\hline Blood lactate, $\mathrm{mmol} / \mathrm{L}$ & $0.97 \pm 0.29$ & $1.22 \pm 0.70$ & $1.37 \pm 0.60$ & 0.007 \\
\hline aPTT admission, s & $1.14 \pm 0.23$ & $1.09 \pm 0.11$ & $1.23 \pm 0.53$ & 0.237 \\
\hline Platelets admission, $\times 10^{9} / \mathrm{L}$ & $215 \pm 88$ & $212 \pm 79$ & $242 \pm 79$ & 0.243 \\
\hline Platelets peak, $\times 10^{9} / \mathrm{L}$ & $394 \pm 187$ & $391 \pm 142$ & $439 \pm 165$ & 0.335 \\
\hline \multicolumn{5}{|l|}{ Thromboprophylaxis during hospitalization } \\
\hline $\begin{array}{l}\text { Standard-dose anticoagulant thromboprophylaxis, } n \text { (\%) } \\
\text { Enoxaparin } 40 \mathrm{Mg} / 0.4 \mathrm{~mL} \\
\text { Prophylactic-dose UFH } \\
\text { Fondaparinux } 2.5\end{array}$ & $\begin{array}{l}45(62.5) \\
44(61.1) \\
0(0) \\
1(1.4)\end{array}$ & $\begin{array}{l}23(67.6) \\
23(67.6) \\
0(0) \\
0(0)\end{array}$ & $\begin{array}{l}23(52.3) \\
11(25) \\
2(4.5) \\
0(0)\end{array}$ & 0.351 \\
\hline $\begin{array}{l}\text { Intermediate dose anticoagulant thromboprophylaxis, } n(\%) \\
\text { Enoxaparin } 40 \mathrm{Mg} / 0.4 \mathrm{~mL} \text { BID }\end{array}$ & $\begin{array}{l}13(18.1) \\
13(18.1)\end{array}$ & $\begin{array}{l}6(17.6) \\
6(17.6)\end{array}$ & $\begin{array}{l}8(18.2) \\
8(18.2)\end{array}$ & 0.998 \\
\hline Therapeutic dose anticoagulant thromboprophylaxis, $n$ (\%) & $14(19.4)$ & $5(14.7)$ & $1(2.6)$ & 0.245 \\
\hline \multicolumn{5}{|l|}{ Extent of COVID-19 disease on chest CT } \\
\hline Stage $1, n(\%)$ & $10(14.7)$ & $2(6.3)$ & $1(2.6)$ & \multirow[t]{3}{*}{0.001} \\
\hline Stage $2-3, n(\%)$ & $49(72.1)$ & $24(75)$ & $20(51.3)$ & \\
\hline Stage $4, n(\%)$ & $9(13.2)$ & $6(18.6)$ & $18(46.2)$ & \\
\hline \multicolumn{5}{|l|}{ Oxygen } \\
\hline Oxygen demand (maximal oxygen flow rate, L/min) & $4.5 \pm 0.4$ & $6.9 \pm 4.7$ & $8.4 \pm 5.1$ & $<0.001$ \\
\hline \multicolumn{5}{|l|}{ Outcomes } \\
\hline Venous thromboembolic event, $n$ (\%) & $1(1.4)$ & $2(5.9)$ & $14(31.8)$ & $<0.001$ \\
\hline Acute pulmonary embolism, $n(\%)$ & $1(1.4)$ & $2(5.9)$ & $12(27.3)$ & $<0.001$ \\
\hline Deep vein thrombosis, $n(\%)$ & $0(0)$ & $0(0)$ & $2(4.5)$ & 0.087 \\
\hline Transfer to ICU or in-hospital death, $n$ (\%) & $13(18.1)$ & $17(50)$ & $29(65.9)$ & $<0.001$ \\
\hline In-hospital death, $n(\%)$ & $1(1.4)$ & $1(2.9)$ & $6(6.8)$ & 0.284 \\
\hline ICU transfer, $n(\%)$ & $13(18.1)$ & $16(47.1)$ & $29(65.9)$ & $<0.001$ \\
\hline Discharge alive, $n$ (\%) & $64(97)$ & $24(85.7)$ & $33(86.8)$ & 0.087 \\
\hline
\end{tabular}

Abbreviations: aPTT, activated partial thromboplastin time; BID, twice daily; BMI, body mass index; CRP, C-reactive protein; CT, computed tomography; ICU, intensive care unit; UFH, unfractionated heparin; ULN, upper limit of normal.

Note: Continuous variables were expressed as mean \pm standard deviation and categorical variables as counts and percentages. Continuous variables between all groups were compared using ANOVA. Pearson's Chi-squared test was used to compare categorical variables. A $p$-value $<0.05$ was considered significant. Calculations were performed using SPSS 17.0 (SPSS Inc., Chicago, IL, United States). 
as minimal (stage $1<10 \%$ ), moderate (stage $2=10-25 \%$ ), severe (stage $3=25-50 \%$ ), and critical (stage $4>50 \%$ ). The primary outcome was a confirmed diagnosis of any venous thromboembolic event including acute pulmonary embolism (APE) and deep vein thrombosis (DVT). Patients with suspected APE had a CT pulmonary angiography performed based on clinical suspicion (either clinical, echocardiographic, or laboratory parameters). DVT imaging test was performed in subjects with signs or symptoms of DVT. The secondary outcome was the composite of death or transfer to ICU. The present study was approved by the Research Ethics Committee of Strasbourg Hospital (authorization CE-2020-57) and waived the need of informed consent.

A total of 150 consecutive patients with confirmed COVID19 infection, thromboprophylaxis, and available D-dimers kinetics were admitted to general wards between February 25 and April 19, 2020. According to the staging scheme, 72 (48\%) patients were in stage 1,34 (22.7\%) patients were in stage 2 , and 44 (29.3\%) patients were in stage 3 (-Table 1). Patients in more advanced stages presented with higher venous thromboembolism (VTE) risk evaluated via the Padua Prediction Score and the IMPROVE score on admission to hospital. According to the staging scheme, baseline aPTT, leukocytes, and platelets peak were similar among the three hemostatic groups. Patients in more advanced stages had higher $\mathrm{C}$-reactive protein (CRP) and fibrinogen peak ( - Fig. 1). At least one chest CT was available in 139 patients ( 92.7 of the global cohort). Chest CT severity score was significantly associated with higher CAHA stages. Similarly, higher oxygen requirements were evidenced with more advanced stages. Likewise, a stepwise increase in lactate levels that paralleled CAHA stages was evidenced. The incidence of
VTE was $1.4 \%$ in stage $1,5.9 \%$ in stage 2 , and $31.8 \%$ in stage 3 $(p<0.001)$. APE was diagnosed in 15 patients $(10 \%)$ and there was a significant stepwise increase in events according to CAHA staging $(p<0.001)$. VTE was diagnosed in median 8(3-13) days after admission and 15 (12-22) days after COVID-19-related symptoms onset. The composite of death or transfer to ICU occurred in 59 patients (39.3\%). The incidence of the secondary outcome was $18.1 \%$ in stage $1,50 \%$ in stage 2 , and $65.9 \%$ in stage $3(p<0.001)$. The rate of this composite outcome was threefold higher in CAHA stage 2 and 3 compared with stage 1, but mortality did not differ significantly among the groups.

This study is, to the best of our knowledge, the first investigation specifically designed to assess the prevalence and prognosis impact of the new CAHA staging among COVID-19 patients hospitalized in non-ICU wards. We observed a high rate of CAHA stage 2 and 3 accounting for approximately $50 \%$ of the cohort. D-dimer increased levels were reported to be associated with severity of COVID-19 disease $\mathrm{e}^{1,7,8}$ and CAHA stage 2 and 3 patients may undoubtedly benefit from critical care support as suggested by Thachil et al. ${ }^{5}$ This staging scheme has the potential to identify the patients who may benefit from early elective ICU transfer versus those who can be managed in wards.

Interestingly, aPTT on admission and platelets on admission or at peak were similar between the three groups of patients and did not appear to provide additional prognostic value. Adding the peak of CRP or fibrinogen in the stage definition may be worth considering to improve its discrimination. Indeed, a stepwise increase in CRP or fibrinogen peaks was evidenced for each increment in the stage of CAHA.
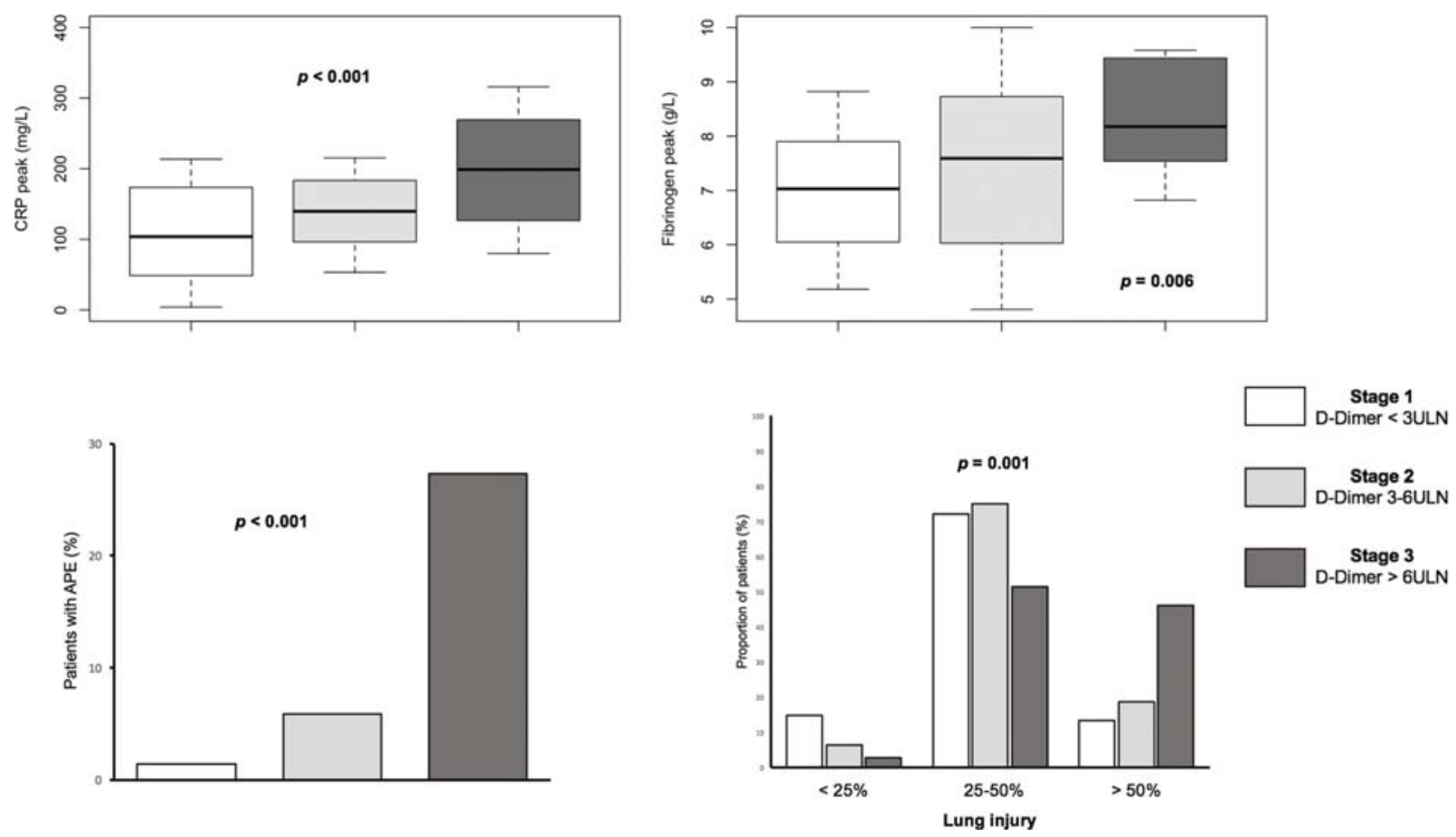

Fig. 1 CRP peak, fibrinogen peak, acute pulmonary embolism, and extent of coronavirus disease 2019 (COVID-19) disease on chest CT according to the three stages COVID-19-associated hemostatic abnormalities (CAHA) classification. The extent of COVID-19 disease on chest CT was assessed as pulmonary injuries extension in percentage of the total pulmonary field and classified as minimal (stage $1<10 \%$ ), moderate (stage $2=10-25 \%$ ), severe (stage $3=25-50 \%$ ), and critical (stage $4>50 \%$ ). APE, acute pulmonary embolism; CRP, C-reactive protein; CT, computed tomography; ULN, upper limit of normal. 
Our study emphasized the interrelationship between the extent of COVID-19 disease on chest CT, oxygen requirement, lactate levels, and a gradual increase in CAHA grading. Recent reports provided important insight into the relationship between hypercoagulability, thromboinflammation, and acute lung injury. ${ }^{9-11}$ While pulmonary microthrombosis has been reported in small autopsy series, ${ }^{12,13}$ no studies have yet been able to correlate chest CT severity score with the extent of COVID-19-induced coagulopathy or PE. Furthermore, we described a gradual increase in VTE occurrence and the composite risk of ICU transfer and short-term mortality with each increment in the staging. The risk of VTE in the short term was increased when CAHA grade was $\geq 2$. Hence, this threshold could be used to consider early aggressive strategies ${ }^{14}$ including early VTE imaging screening, intermediate dose or therapeutic (full dose) anticoagulation, and critical care support.

This study shows that the CAHA staging classification provides incremental prognostic value in non-ICU COVID19 patients. This staging system may be helpful to identify coronavirus patients at higher risk who could benefit from early VTE imaging screening, intermediate dose or therapeutic (full dose) anticoagulation, and early critical care support. In the subset of patients harboring a stage $\geq 2$, active clinical and biological surveillance should be considered.

\section{Authors' Contributions}

B.M.: drafting of the manuscript and critical revision for important intellectual content; A.T.: data collection and drafting of the manuscript; A.C.: data collection and interpretation; A.C.: data collection and interpretation; K.M.: data collection and interpretation; C.S.: data collection and interpretation; I.L.-L.: data collection and interpretation; L.S.: data collection and interpretation; L.G.: data collection and interpretation; M.O.: data collection, interpretation, and critical revision for important intellectual content; P.O.: interpretation of data and critical revision for important intellectual content; L.J.: drafting of the manuscript, interpretation of data, and critical revision for important intellectual content; O.M.: study conception and design, data collection and interpretation, drafting of the manuscript, and critical revision for important intellectual content. The manuscript has been read and approved for submission by all authors. All the authors take responsibility for all aspects of the reliability and freedom from bias of the data presented and their discussed interpretation.

\section{Funding}

None declared.
Conflict of Interest

M.O. reports personal fees from Canon Medical Systems Europe, outside the submitted work.

\section{References}

1 Leonard-Lorant I, Delabranche X, Severac F, et al. Acute pulmonary embolism in COVID-19 patients on CT angiography and relationship to D-dimer levels. Radiology 2020:201561

2 Spiezia L, Boscolo A, Poletto F, et al. COVID-19-related severe hypercoagulability in patients admitted to intensive care unit for acute respiratory failure. Thromb Haemost 2020;120(06): 998-1000

3 Zhai Z, Li C, Chen Y, et al; Prevention Treatment of VTE Associated with COVID-19 Infection Consensus Statement Group. Prevention and treatment of venous thromboembolism associated with coronavirus disease 2019 infection: a consensus statement before guidelines. Thromb Haemost 2020;120(06):937-948

4 Violi F, Pastori D, Cangemi R, Pignatelli P, Loffredo L. Hypercoagulation and antithrombotic treatment in coronavirus 2019: a new challenge. Thromb Haemost 2020;120(06):949-956

5 Thachil J, Cushman M, Srivastava A. A proposal for staging COVID19 coagulopathy. Res Pract Thromb Haemost 2020;4(05): 731-736

6 Revel MP, Parkar AP, Prosch H, et al; European Society of Radiology (ESR) and the European Society of Thoracic Imaging (ESTI). COVID-19 patients and the radiology department - advice from the European Society of Radiology (ESR) and the European Society of Thoracic Imaging (ESTI). Eur Radiol 2020:1-7

7 Zhou F, Yu T, Du R, et al. Clinical course and risk factors for mortality of adult inpatients with COVID-19 in Wuhan, China: a retrospective cohort study. Lancet 2020;395(10229):1054-1062

8 Lippi G, Favaloro EJ. D-dimer is associated with severity of coronavirus disease 2019: a pooled analysis. Thromb Haemost 2020;120(05):876-878

9 McGonagle D, O'Donnell JS, Sharif K, Emery P, Bridgewood C. Immune mechanisms of pulmonary intravascular coagulopathy in COVID-19 pneumonia. Lancet 2020;2(7):E437-E445

10 Ranucci M, Ballotta A, Di Dedda U, et al. The procoagulant pattern of patients with COVID-19 acute respiratory distress syndrome. J Thromb Haemost 2020;18(07):1747-1751

11 Ciceri F, Beretta L, Scandroglio AM, et al. Microvascular COVID-19 lung vessels obstructive thromboinflammatory syndrome (MicroCLOTS): an atypical acute respiratory distress syndrome working hypothesis. Crit Care Resusc 2020;22(02):95-97

12 Dolhnikoff M, Duarte-Neto AN, de Almeida Monteiro RA, et al. Pathological evidence of pulmonary thrombotic phenomena in severe COVID-19. J Thromb Haemost 2020;18(06):1517-1519

13 Ackermann M, Verleden SE, Kuehnel M, et al. Pulmonary vascular endothelialitis, thrombosis, and angiogenesis in Covid-19. N Engl J Med 2020;383(02):120-128

14 Bikdeli B, Madhavan MV, Gupta A, et al; Global COVID-19 Thrombosis Collaborative Group. Pharmacological agents targeting thromboinflammation in COVID-19: review and implications for future research. Thromb Haemost 2020;120(07): 1004-1024 